\title{
Pediatric EM
}

\section{Trends in use in a Canadian pediatric emergency department}

\author{
Quynh Doan, MDCM, MHSc, $\mathrm{PhD}^{*^{\dagger}}$; Emerson D. Genuis, $\mathrm{MD}^{\dagger}$; Alvis $\mathrm{Yu}$
}

\section{ABSTRACT}

Introduction: Emergency department (ED) crowding is a significant problem in Canada and has been associated with decreased quality of care in general and pediatric emergency departments (PEDs). Although boarding of admitted patients in the ED is the main contributor to adult ED overcrowding, factors involved in PED crowding may be different. The objective of this study was to report the trend in PED services use and to document the degree of overcrowding experienced in a Canadian PED.

Methods: A retrospective cohort study was conducted using administrative data from a tertiary care PED from 2002 to 2011. The primary outcome was PED use (total volume of visits and case severity per triage levels using the Canadian Triage and Acuity Scale [CTAS] score and admissions). Secondary outcomes included measures of PED overcrowding, such as rates of patients leaving without being seen (LWBS) and length of stay (LOS).

Results: Total volumes increased by $30 \%$ over the 10 -year study period, whereas hospitalizations remained stable at approximately $10 \%$. Trends in CTAS levels did not indicate meaningful changes in the severity of cases treated at our PED. LWBS proportions among CTAS 3, CTAS 4, and CTAS 5 groups and LOS for all CTAS groups progressively and statistically increased from year to year.

Conclusions: Over the course of the study period, there was a substantial increase in PED visits, which likely contributed to the worsening markers of PED flow outcomes. Further study into the effects of PED crowding on patient outcomes is warranted.

\section{RÉSUMÉ}

Introduction: L'engorgement des services des urgences (SU) constitue un problème important au Canada et est associé à une diminution de la qualité des soins, et ce, tant dans les SU générales que dans les SU pédiatriques (SUP). Bien que I'hébergement des malades hospitalisés au SU soit le principal facteur d'engorgement de ces services chez les adultes, il peut en être autrement en ce qui concerne I'engorgement des SU chez les enfants. L'étude visait à faire état de la tendance observée dans les SUP quant à I'utilisation des services et à documenter le degré d'engorgement enregistré dans un SUP au Canada.

Méthode: II s'agit d'une étude de cohortes, rétrospective, réalisée à l'aide de données administratives provenant d'un SUP de soins tertiaires, et recueillies de 2002 à 2011. Le principal critère d'évaluation consistait en la mesure de l'utilisation des SUP (nombre total de consultations, gravité des cas selon I'Échelle canadienne de triage et de gravité [ECTG], admissions). Les critères d'évaluation secondaires comprenaient des mesures de l'engorgement du SUP, telles que les taux de départ sans consultation médicale (DSCM) et la durée du séjour (DS).

Résultats: Le nombre total de consultations a augmenté de $30 \%$ au cours de la période à l'étude (10 ans), mais le taux $\mathrm{d}$ 'hospitalisation est resté stable à environ $10 \%$. L'étude des tendances quant à la gravité des cas traités au SUP, selon I'ECTG, n'a pas révélé de changement important. Enfin, la proportion des DSCM dans les groupes de catégorie 3, 4, et 5 sur I'ECTG et la DS ont augmenté d'année en année, selon une progression statistiquement significative.

Conclusions: Une augmentation importante du nombre de consultations au SUP a été notée au cours de la période à l'étude, ce qui a sans doute contribué à la détérioration des marqueurs de résultats liés au mouvement des patients au SUP. Il serait justifié de mener une autre étude sur les effets de l'engorgement des SUP sur les résultats cliniques.

Keywords: patient flow, pediatric emergency departments, use

Emergency department (ED) overcrowding is a important problem in Canada and has been associated with poor patient health outcomes, low patient satisfaction, and job dissatisfaction for nurses and physicians. ${ }^{1-3}$ Researchers have identified delays in transferring admitted patients to inpatient wards from the $\mathrm{ED}$ (access block) as the leading determinant of

From the *Division of Pediatric Emergency Medicine, Department of Pediatrics; †Department of Emergency Medicine; and $¥ F$ aculty of Medicine, University of British Columbia, Vancouver, BC.

Correspondence to: Dr. Quynh Doan, B429_4480 Oak Street, Vancouver, BC V6H 3N1; qdoan12@gmail.com.

This article has been peer reviewed

(C) Canadian Association of Emergency Physicians 
ambulance diversion and ED overcrowding; however, there are other contributing factors, including a steady increase in patient visits, inadequate access to primary health care, and failure to train and retain ED staff to cope with increasing volumes., ${ }^{4,5}$

Pediatric emergency departments (PEDs) have also been strained with overcrowding. US data estimate 30 million pediatric visits to EDs in $2000,{ }^{6}$ and high PED occupancy has been associated with decreased quality of care for children. ${ }^{78}$ Some studies have suggested that the factors contributing to overcrowding in PEDs are different from those for general or adult EDs. ${ }^{9,10}$ This may be due to differences between PED and general ED flow in a number of ways, including the level of patient acuity and the substantially lower proportion of visits resulting in hospital admission. ${ }^{6,11}$ A recent survey of Canadian PED directors and pediatric emergency medicine fellowship program directors suggested that patient volume and ED operational procedures may be more significant contributors to overcrowding than access block in the PED.' Another study, which prospectively examined factors contributing to $\mathrm{PED}$ overcrowding, identified patient volume as the most significant factor contributing to this problem. ${ }^{10}$ As patient volumes increased, worsening in multiple markers of PED system performance (flow), such as length of stay (LOS) and rates of patients leaving the ED before being seen (LWBS), were observed. ${ }^{8}$ As such, LOS and LWBS rates have been proposed as markers of PED crowding."

Although PED visit volumes in the United States have been stable, ${ }^{12}$ the situation in Canadian PEDs has not been widely reported. The goal of this study was to report the trend in PED services use (total and per capita volumes, and acuity) and to document the degree of overcrowding experienced in a Canadian PED. Although general or adult ED overcrowding is a reasonably well-studied subject, relatively little research has been done quantifying PED overcrowding and identifying factors contributing to it. The results of this study will provide insights into the issue of PED overcrowding, eventually leading to the development of strategies to improve PED patient flow.

\section{METHODS}

\section{Design, setting, and population}

We conducted a retrospective cohort study analyzing administrative data collected by the Provincial Health
Services Authority (PHSA) performance measurements and reporting services between 2002 and 2011. These data were collected through direct computerized entries at the time of ED visits and validated against paperbased health records. We analyzed visit data from the BC Children's Hospital (BCCH) PED, the only tertiary care pediatric referral centre in British Columbia, which currently receives approximately 40,000 annual visits. The BCCH PED provides care to children and youth up to 17 years of age with exception to certain young adults with ongoing pediatric subspecialty needs. Occasionally, adult patients are assessed, stabilized, and transferred to a general hospital when they require emergency help on site.

\section{Objectives and outcome measures}

The primary objective was to document a trend in PED use between 2002 and 2011. Changes were assessed in the number of yearly PED visits and the rate of PED visits per capita. $\mathrm{BC}$ population under the age of 17 was determined according to population estimates from BC Stats, the central statistical agency of the Province of British Columbia. ${ }^{13}$ The change in the acuity of PED visits during this time period was evaluated. The acuity and severity of PED visits were measured using the pediatric Canadian Triage and Acuity Scale (CTAS) ${ }^{14}$ and the number of patients admitted to the hospital. This tool has good interrater agreement, has been validated, and has been found to correlate with markers of severity, patient outcome, and PED resource use such as ED LOS, admission to the hospital, and admission to the pediatric intensive care unit. ${ }^{15-17}$

Our secondary objectives were to assess if the change in PED use was accompanied with changes in system performance outcomes, such as mean and median total LOS in the PED and the LWBS rate. These outcomes were assessed within the level of acuity as determined by the CTAS score. In addition, we explored other demographic factors that may be involved in PED use, such as the average age of PED patients and the patient's geographic area of residence.

\section{Data validation and analyses}

Administrative data were reviewed by two research assistants for obvious chronological errors (e.g., time seen by the physician or time discharged occurring before time registered). These were highlighted and 
reviewed again for the same purpose by two investigators (E.D.G. and Q.D.) sequentially. Confirmed erroneous time stamps were removed and considered missing data, and truly missing data (e.g., time stamps were never entered) were identified.

We used descriptive statistics and scatter plots to report trends in PED annual visits, PED annual visits per capita, and all other outcome measures, stratified by CTAS levels and calendar years. We conducted the Kruskal-Wallis test ( $S A S$ statistical software, version 9.3, SAS Institute Inc., Cary, NC) to assess if the LOS significantly changed over time and the chi-square test to assess if yearly admission rates were significantly different during the study period.

\section{RESULTS}

\section{Trend in PED use}

We reviewed and analysed data for 390,868 visits from January 1, 2002, to December 31, 2011. The annual number of visits to the BCCH PED increased by $30 \%$ between 2002 and 2011 (from 33,903 to 44,100 annual visits). The overall rate of PED visit per capita, using a provincial census of children under 17 years old, increased by $35 \%$ in the same period (from 4.1 visits per 100 children in 2002 to 5.6 visits per 100 children in 2011). The increase was not distributed evenly among levels of acuity. The number of visits triaged to CTAS 1 and CTAS 3 remained fairly constant $(<10 \%$ increase). The number of visits triaged to CTAS 4 increased by almost $30 \%$, to CTAS 2 doubled, and to CTAS 5 almost quadrupled (Table 1). The trend in PED visit per capita mirrored that of the absolute annual visit.

The overall proportions of admission during the study period did not change in a clinically meaningful way; however, there were significant changes when the admission proportions were stratified by CTAS level. Although the trend was most meaningful for visits in CTAS 1 (increased) and CTAS 2 (decreased), the proportion of PED visits resulting in a hospital admission was found to be statistically significant from year to year for all five CTAS levels (Table 2).

\section{Trend in PED markers of flow}

We reviewed LOS data stratified by CTAS levels of acuity. The proportion of missing data on this

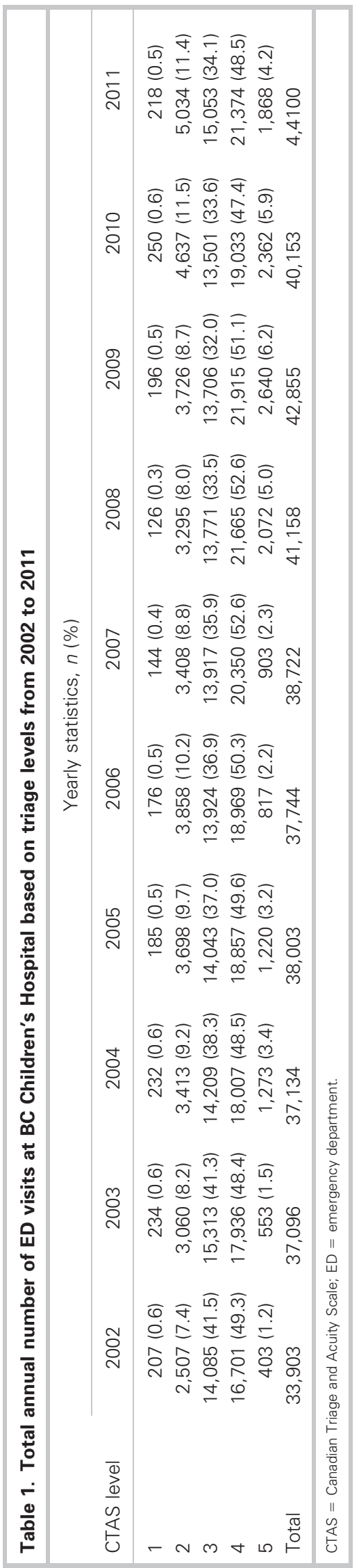

$2014 ; 16(5)$

407 


\begin{tabular}{|c|c|c|c|c|c|c|c|c|c|c|c|}
\hline \multirow[b]{2}{*}{ CTAS level } & \multicolumn{10}{|c|}{ Admission (\%) based on year } & \multirow[b]{2}{*}{$p$ value } \\
\hline & 2002 & 2003 & 2004 & 2005 & 2006 & 2007 & 2008 & 2009 & 2010 & 2011 & \\
\hline 1 & 53.1 & 47.4 & 56.9 & 53.5 & 59.7 & 54.9 & 59.5 & 60.0 & 65.6 & 67.9 & 0.0002 \\
\hline 2 & 39.9 & 36.2 & 36.4 & 37.2 & 39.3 & 40.5 & 36.5 & 34.0 & 32.4 & 32.7 & $<0.0001$ \\
\hline 3 & 15.4 & 12.8 & 14.0 & 13.0 & 14.3 & 15.2 & 14.5 & 11.2 & 11.6 & 12.7 & $<0.0001$ \\
\hline 4 & 1.0 & 1.4 & 1.8 & 1.5 & 1.8 & 1.9 & 1.9 & 1.1 & 1.3 & 1.3 & $<0.0001$ \\
\hline 5 & 2.7 & 0.5 & 2.4 & 3.8 & 1.8 & 1.8 & 1.3 & 1.0 & 1.9 & 1.2 & $<0.0001$ \\
\hline
\end{tabular}

outcome measure varied from year to year and among CTAS levels. Overall, missing data ranged from 0.1 to $2.7 \%$ over the study period. There was a trend toward the highest missing data among the highest acuity levels, with time of ED departures missing for 0.5 to $2.7 \%$ of all CTAS 1 visits and lowest missing data among CTAS 5 level visits (0 to $0.3 \%$ ).

The median LOS times stratified by CTAS levels for the study period are presented in Figure 1. Comparisons of LOS times from year to year were statistically significant for every CTAS level $(p<0.0001)$.

The proportion of LWBS observed at BCCH PED remained stable for the highest acuity levels (CTAS 1 and CTAS 2); however, the LWBS rate increased significantly for CTAS 3, CTAS 4, and CTAS 5 level visits between 2002 and 2011 ( $p<0.0001$ for each of these CTAS levels), as displayed in Figure 2.

\section{PED users' demographic patterns}

The mean age of patients visiting the PED remained consistent between 5.1 and 5.3 years old, and the median age varied between 3 and 4 years old. Through

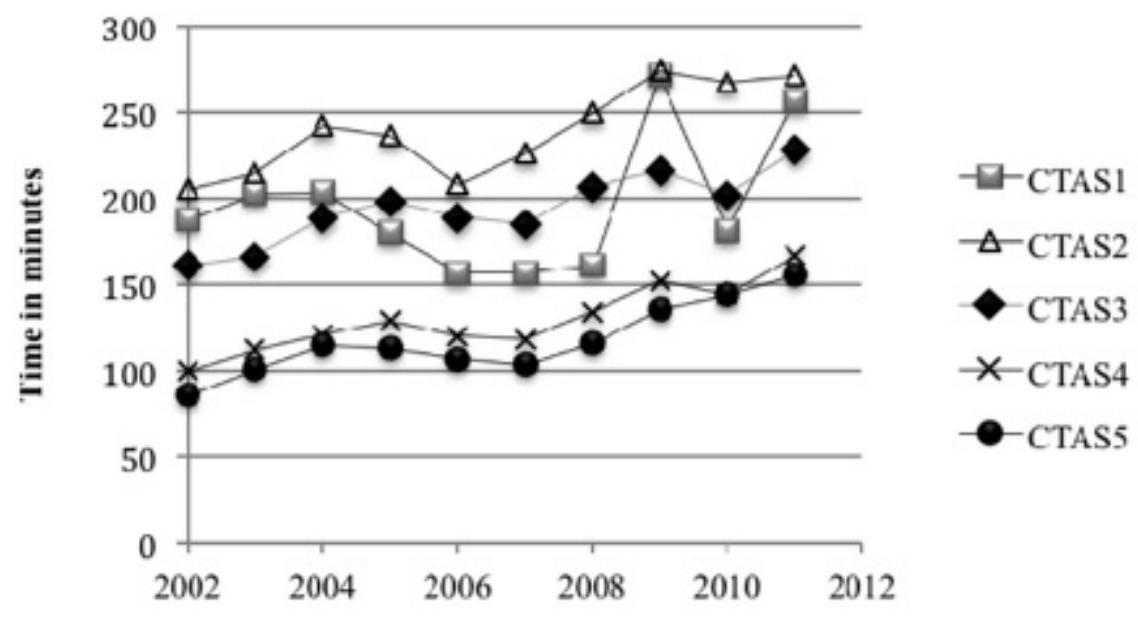

the study period, the vast majority $(80 \%)$ of patients' areas of residence were consistently from Vancouver and the surrounding communities. Over the course of the study, the proportion of PED patients from Vancouver was noted to decrease steadily from $56.6 \%$ in 2002 to $48.5 \%$ in 2011 . The only region where the proportion of patients visiting our PED increased over the course of the study time period was the Fraser Valley, which covers an area between approximately 15 and $100 \mathrm{~km}$ away from the PED.

\section{DISCUSSION}

This study provides an overview of PED use and its associated markers of PED flow over a 10-year period. We have demonstrated an increase in the number of visits to the BCCH PED, both in absolute numbers and per capita rate among children less than 17 years of age. We also found that there has been a rise in the proportion of PED LOS and LWBS cases, suggesting deterioration in PED flow during the period where use was increased. The overall increase in the total number of visits was not distributed evenly among the five

Figure 1. Trends in median length of stay based on triage levels at the BC Children's Hospital emergency department from 2002 to 2011. CTAS $=$ Canadian Triage and Acuity Scale. 


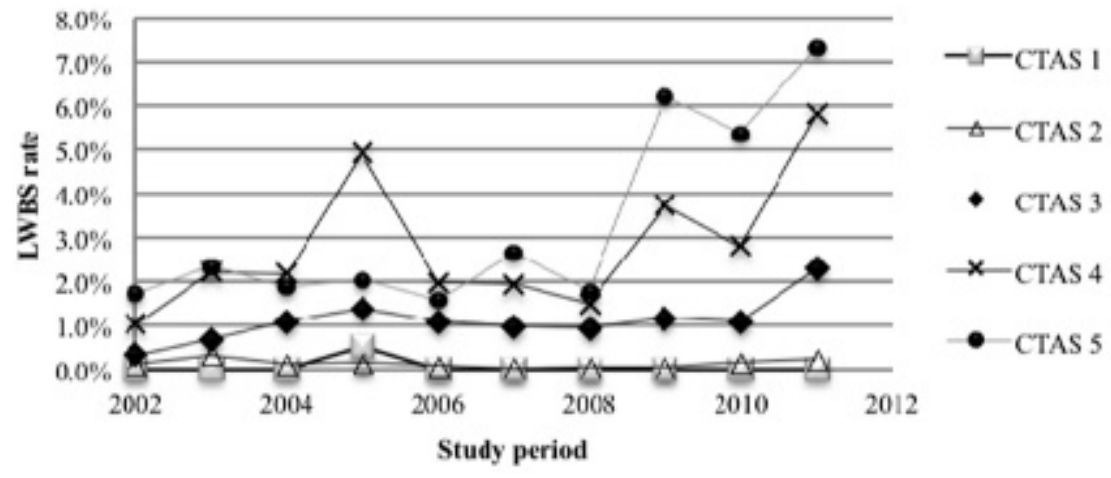

Figure 2. Rate of patients leaving without being seen by triage levels at BC Children's Hospital emergency department from 2002 to 2011. CTAS $=$ Canadian Triage and Acuity Scale; LWBS = left without being seen. levels of acuity. Although the largest relative increase was seen in the nonurgent visits (CTAS 5), there was also a significant increase in the emergent visits.

Severity could be measured coarsely by CTAS and admissions in this study. The pediatric CTAS tool was implemented in 2001 and underwent some revisions in 2008 to simplify the triage process and amalgamate the pediatric and adult CTAS guidelines in 2008. ${ }^{14}$ There are no reports that these revisions resulted in systematic changes or "up-triaging" in pediatric patients, and there was no obvious change in PED trends noted after 2008 in our study. Fluctuations in the severity of conditions being managed at our PED can also be gauged by the admission trends. Admissions for patients requiring resuscitation (CTAS 1) increased every year; however, the admission rate for emergent visits (CTAS 2) has been decreasing and that of the lower acuity levels has remained stable. This suggests that the severity of conditions for the 0.3 to $0.6 \%$ of PED visits triaged to CTAS 1 has increased over time. The data on changes in patient visit volumes in the low-acuity visits (CTAS 4-5), combined with the decrease in admission rate in CTAS 2 visits, would suggest that the overall acuity of visits to our PED has decreased.

The 30\% increase in PED volume was met with a $2.7 \%$ increase in nursing coverage in 2007 in the form of a psychiatry liaison nurse and a $4.9 \%$ increase in nursing coverage to work directly with the $2 \%$ increase in physician coverage in 2010 in the form of a rapid assessment and treatment shift in the evenings during the winter. There was no change in physical space in the PED. This may be the explanation for the steady increase in LOS for all CTAS levels and LWBS proportions for CTAS 1 to 3 . Our findings are consistent with the notion that increasing volume of visits (without matching resource supplementation) is associated with worsening flow outcomes in a PED, as has been suggested in previous studies. ${ }^{8,10}$

The finding that children from surrounding communities, particularly the Fraser Valley, contribute to an increasing proportion of our PED visits is most likely related to the fact that during the study period, the population under 18 years of age has increased at a higher pace in the Fraser Valley than in Vancouver. ${ }^{13}$ It could also potentially indicate increased patient preference in choosing to visit a PED further away rather than visit the general ED in their own community.

Limitations to this study's findings include the inherent constraints associated with retrospective administrative databases, such as missing data and the risk of errors in the initial data entry; however, these numbers were small in this study. Although the time of arrival is automatically recorded at the time of registration, the time of discharge is entered manually by physicians and nurses to the best of their effort at the time of disposition. The timing of this recording may be variable, and its accuracy cannot be verified. In addition, this study's results do not relate the deterioration in measures of PED flow with negative patient effects and therefore do not guide us in determining the threshold beyond which PED overcrowding affects patient outcomes.

\section{CONCLUSION}

This study establishes that our PED has not been spared from overcrowding. Although the acuity distribution of our PED visits has not markedly changed, the total volume of visits has increased significantly and is likely the reason for the important flow deteriorations and exacerbation of overcrowding. It is important that future research measure the impact of PED overcrowding on children's outcomes to direct 
efforts toward evaluating strategies to alleviate PED overcrowding in Canada.

Competing interests: None declared.

\section{REFERENCES}

1. Guttmann A, Schull MJ, Vermeulen MJ, Stukel TA. Association between waiting times and short term mortality and hospital admission after departure from emergency department: population based cohort study from Ontario, Canada. BMf 2011;342:d2983, doi:10.1136/bmj.d2983.

2. Richardson DB. Increase in patient mortality at 10 days associated with emergency department overcrowding. Med 7 Aust 2006;184:213-6.

3. Rondeau K V, Francescutti LH. Emergency department overcrowding: the impact of resource scarcity on physician job satisfaction. 7 Healthc Manag 2005;50:327-40.

4. Schull MJ, Lazier K, Vermeulen M, et al. Emergency department contributors to ambulance diversion: a quantitative analysis. Ann Emerg Med 2003;41:467-76, doi:10.1067/ mem.2003.23.

5. Ospina MB, Bond K, Schull M, et al. Key indicators of overcrowding in Canadian emergency departments: a Delphi study. CFEM 2007;9:339-46.

6. Bourgeois FT, Shannon MW. Emergency care for children in pediatric and general emergency departments. Pediatr Emerg Care 2007;23:94-102, doi:10.1097/PEC.0b013e3180302c22.

7. Sills MR, Fairclough DL, Ranade D, et al. Emergency department crowding is associated with decreased quality of analgesia delivery for children with pain related to acute, isolated, long-bone fractures. Acad Emerg Med 2011;18:13308, doi:10.1111/j.1553-2712.2011.01136.x.

8. Timm NL, Ho ML, Luria JW. Pediatric emergency department overcrowding and impact on patient flow outcomes. Acad Emerg Med 2008;15:832-7, doi:10.1111/j. 1553-2712.2008.00224.x.

9. Stang AS, McGillivray D, Bhatt M, et al. Markers of overcrowding in a pediatric emergency department. Acad Emerg Med 2010;17:151-6, doi:10.1111/j.1553-2712.2009. 00631.x.

10. Weiss SJ, Ernst AA, Sills MR, et al. Development of a novel measure of overcrowding in a pediatric emergency department. Pediatr Emerg Care 2007;23:641-5, doi:10.1097/PEC. 0b013e31814a69e2.

11. Sinclair D. Emergency department overcrowding - implications for pediatric emergency medicine. Emerg Med 2007;12:491-4.

12. National Center for Health Statistics. Health, United States, 2012: with special features on emergency care. (05/30/2013). Hyattsville (MD); 2012. Available at: http://www.cdc.gov/ nchs/data/hus/hus12.pdf\#085 (accessed July 3, 2013).

13. British Columbia Statistics. BC Stats population estimates. 2012. Available at: http://www.bcstats.gov.bc.ca/StatisticsBySubject/ Demography/PopulationEstimates.aspx (accessed January 7, 2013).

14. Warren DW, Jarvis A, Leblanc L, Gravel J. Revisions to the Canadian Triage and Acuity Scale Paediatric Guidelines (PaedCTAS ). CFEM 2008;10:224-32.

15. Gravel J, Gouin S, Goldman RD, et al. The Canadian Triage and Acuity Scale for children: a prospective multicenter evaluation. Ann Emerg Med 2012;60:71-7.e3, doi:10.1016/ j.annemergmed.2011.12.004.

16. Gravel J, Manzano S, Arsenault M. Validity of the Canadian Paediatric Triage and Acuity Scale in a tertiary care hospital. CFEM 2009;11:23-8. Available at: http://www.ncbi.nlm.nih. gov/pubmed/19166636 (accessed January 14, 2013).

17. Gravel J, Gouin S, Manzano S, et al. Interrater agreement between nurses for the Pediatric Canadian Triage and Acuity Scale in a tertiary care center. Acad Emerg Med 2008; 15:12627, doi:10.1111/j.1553-2712.2008.00268.x. 